\title{
COAGULATION HEMOSTASIS INDICES AFTER HEMORRHAGIC STROKE, DEVELOPED AS A COMPLICATION OF ESSENTIAL HYPERTENSION
}

\section{O. Tkachyshyn}

The aim: to determine the peculiarities of the indices of coagulation hemostasis in patients with the former occurrence of hemorrhagic stroke, developed as a complication of essential hypertension, in comparison to the hypertensive patients without complications.

Materials and methods. There were formed 2 groups of patients: the main group and the comparison group. The main group included 20 patients (10 women and 10 men, middle age 52.9 $\pm 1.7(\mathrm{M} \pm \mathrm{m})$ years old) who had undergone hemorrhagic stroke as a complication of essential hypertension 6 months and more previously, had no normalization of blood pressure over this period of time. The comparison group included 20 patients (10 women and 10 men, middle age $52.5 \pm 1.7$ years old) suffered from essential hypertension without complications. They were matched groups according to key indicators. All the above-mentioned people underwent fasted analysis of venous blood with detection of coagulation hemostasis indices.

Results. In the main and the comparison group the indices of coagulation hemostasis were the following ones, respectively: thrombin time $10.6 \pm 0.6$ and $11.5 \pm 0.8 \mathrm{~s}$, international normalized ratio $1.0 \pm 0.1$ and $1.0 \pm 0.1$, activated partial thromboplastin time $50.4 \pm 2.1$ and $44.7 \pm 1.8 \mathrm{~s}$ (p<0.05), protein $C 139.2 \pm 8.0$ and $143.8 \pm 10.2 \%$, fibrinogen $2,4 \pm 0.4$ and $2.6 \pm 0.3 \mathrm{~g} / \mathrm{l}$, soluble fibrin-monomer complexes $3.9 \pm 0.2$ and $3.7 \pm 0.1 \mu \mathrm{g} / \mathrm{mL}$, XIIa-dependent fibrinolysis $6.3 \pm 0.9$ and $10.2 \pm 0.6 \min (p<0.05)$, antithrombin-III $90.0 \pm 6.6$ and $76.1 \pm 6.8 \%$.

Conclusions. In the main group relatively to the comparison group there was slowing of the internal pathway of coagulation hemostasis with the quicker fibrinolysis. There was detected that $100 \%$ of patients from the main group had at least one of the following factors out of normal values and with predisposition to bleeding: activated partial thromboplastin time $>48 \mathrm{~s}$, XIIa-dependent fibrinolysis $<5 \mathrm{~min}$, fibrinogen $<2 \mathrm{~g} / \mathrm{l}$, or antithrombin-III $>120 \%$. This information should be taken into account while prescribing the treatment, influencing hemostasis indices, in a category of hypertensive patients after hemorrhagic stroke

Keywords: hemorrhagic stroke, essential hypertension, coagulation hemostasis, thrombin time, fibrinogen, protein $C$, soluble fibrin-monomer complexes, international normalized ratio, XIIa-dependent fibrinolysis, activated partial thromboplastin time, antithrombin-III

Copyright (C) 2021, O. Tkachyshyn.

This is an open access article under the CC BY license (http://creativecommons.org/licenses/by/4.0).

\section{Introduction}

Hemorrhagic stroke is a severe complication of essential hypertension (EH) with a high risk of death in the acute and subacute phases. However, due to the development of technology and improving the efficiency and quality of emergency neurosurgical care for such patients [1], it seems obvious that more of them will survive in the early periods after a stroke. Thus, work on the study of the peculiarities of the processes in the body of such persons will become increasingly important. After the rescuing procedures at the acute phase, it is necessary to control factors of further cerebrovascular system injury. Blood pressure and low-density lipoproteins (LDL) level are among of them taking into account the findings of more developed atherosclerosis of the major cervical arteries in this category of patients, published in the previous works [2].

In atherosclerosis, it has been shown that diminishing of the elevated levels of total cholesterol and LDL reduces the risk of cardiovascular events and death from any cause $[3,4]$. In order to reduce LDL to prevent the progression of atherosclerosis, a drug from the group of 3-hydroxy-3-methylglutaryl-coenzyme A reductase in- hibitors (statins) is usually selected. The practical implication of the study lies in the plane of further prophylaxis of the vascular damage, including the statins as there are indications for there usage in this category of patients. However, in many studies there are conflicting data on the feasibility and safety of correction of lipid profile in patients who have suffered a hemorrhagic stroke, due to the increased risk of re-bleeding $[5,6]$. There are present several concerns in relation to the lipid-lowering therapy in patients after the hemorrhagic stroke [7]. The reason is that statins reduce thrombin production [8]. This factor should be taken into account that highlights the necessity for better understanding the coagulation hemostasis.

In this regard, the statin treatment should be provided under the control of coagulation hemostasis. Determination of hemostasis indices can provide valuable information on the progression of lesions of the already compromised cardiovascular system in $\mathrm{EH}$ patients in the later stages after hemorrhagic stroke. Prevention of rehemorrhage emphasizes avoidance of anticoagulation and strict blood pressure control. Long-term management of patients after the episode of intracerebral hemorrhage requires correctly identifying the underlying etiology 
and, when possible, correcting it [9]. It is noted that achieving a balance between the risk of recurrent hemorrhagic stroke and the prevention of ischemic vascular disease through statin treatment is a difficult task for this cohort of patients [10].

There is lack information about the coagulation hemostasis peculiarities in such patients in a half-year and more after the hemorrhagic stroke incidence. Nevertheless, there have been found the disturbances in coagulation hemostasis in such patients [11]. Besides that, there has been an attempt to identify the most responsible hemostasis component for hemorrhagic stroke. However, the results of one of the meta-analysis showed that the study component FXIII-A Val34Leu polymorphism was not associated with intracerebral hemorrhage risk, despite of the preliminary findings [12].

At the same time, patients who have suffered a hemorrhagic stroke as a complication of EH have an increased risk of further complications and death [13], which necessitates the improvement of diagnostic measures for timely detection and correction of risk factors of EH progression.

The aim of the study was to determine the peculiarities of the indices of coagulation hemostasis in patients with the former occurrence of hemorrhagic stroke, developed as a complication of essential hypertension, in comparison to the hypertensive patients without complications.

\section{Materials and methods}

The study was conducted at the clinical base of the department of propedeutics of internal medicine No. 1 of the Bogomolets National Medical University, which is located at Kyiv Railway Clinical Hospital No. 2 of Branch "Health Center" of the Joint Stock Company "Ukrainian Railway", in January 2021.

The study involved 40 people (20 women and 20 men). The main group included 20 patients (10 women and 10 men, middle age $52.9 \pm 1.7$ years old) who had undergone a hemorrhagic stroke as a complication of $\mathrm{EH}$ 6 months and more previously, had no spontaneous normalization of blood pressure over this period of time. The comparison group included 20 patients (10 women and 10 men, middle age $52.5 \pm 1.7$ years old).

The clinical trial was conducted in accordance with the Helsinki Declaration of the World Medical Association "Ethical Principles of Medical Research with Human Participation" (1964, updated in 2000). The patient or his legal representative filled in the informed consent (expert opinion of the Ethics Commission of the
Bogomolets National Medical University dated October 26, 2016, protocol No. 98).

The study was conducted in accordance with the Agreement No. 07 on scientific cooperation between the State Institution "Romodanov Neurosurgery Institute of the National Academy of Medical Sciences of Ukraine" and the Bogomolets National Medical University dated January 21, 2016.

The patients of the main group underwent a hemorrhagic stroke associated with EH more than 6 months ago, did not have normalization of blood pressure after its episode and recovered up to $50-100$ points according to the Barthel scale. The patients were examined on average $12.5 \pm 0.8$ months after hemorrhagic stroke occurrence. The criterion for inclusion of patients into the study was EH, stage II, before the development of hemorrhagic stroke. Exclusion criteria were non-EH-related factors of hemorrhagic stroke development. The choice for examination of the patients in 6 months and more after the hemorrhagic stroke episode was due to the need for patients to be in a stable phase [14].

The patients were offered to undergo a comprehensive examination of coagulation hemostasis panel. All these 40 patients underwent fasting venous blood analysis for the coagulogram indices. Platelet-poor plasma obtained by centrifuging blood at $3000 \mathrm{rpm}$ (1500 g) for 20 min was examined. There were used standardized test systems of Scientific Development and Production Center "Renam" origin according to their instructions [15]. The laboratory tests were held on a coagulometer Amelung KC 1A micro (Heinrich Amelung GmbH, Germany). The following coagulogram parameters were determined: thrombin time, international normalized ratio, activated partial thromboplastin time, protein $\mathrm{C}$, fibrinogen, soluble fibrin-monomer complexes, XIIa-dependent fibrinolysis, antithrombin-III [16].

Statistical processing of the obtained data was performed using IBM SPSS Statistics Base v.22. The difference between the compared parameters with the normal distribution of the variants was evaluated by Student's t-test, between those, which had an abnormal distribution of the variants, - by the Mann-Whitney U-test.

\section{Research results}

The presented study parameters provide with the information concerning hemostasis system itself, anticoagulation and fibrinolysis systems. The aggregate data on the results of coagulogram indices of both groups is given in the Table 1 .

Table 1

Indices of coagulation hemostasis of the study groups $(\mathrm{M} \pm \mathrm{m})$

\begin{tabular}{|c|c|c|c|}
\hline Index & Main group, $n=20$ & Comparison group, $n=20$ & Reference values \\
\hline Thrombin time, $\mathrm{s}$ & $10.6 \pm 0.6$ & $11.5 \pm 0.8$ & $9-13$ \\
\hline International normalized ratio & $1.0 \pm 0.1$ & $1.0 \pm 0.1$ & $0.85-1.15$ \\
\hline Activated partial thromboplastin time, $\mathrm{s}$ & $50.4 \pm 2.1 *$ & $44.7 \pm 1.8$ & $36-48$ \\
\hline Protein $\mathrm{C}, \%$ & $139.2 \pm 8.0$ & $143.8 \pm 10.2$ & $65-145$ \\
\hline Fibrinogen, $\mathrm{g} / \mathrm{l}$ & $2.4 \pm 0.4$ & $2.6 \pm 0.3$ & $2-4$ \\
\hline Soluble fibrin-monomer complexes, $\mu \mathrm{g} / \mathrm{mL}$ & $3.9 \pm 0.2$ & $3.7 \pm 0.1$ & $3-4$ \\
\hline XIIa-dependent fibrinolysis, min & $6.3 \pm 0.9 *$ & $10.2 \pm 0.6$ & $5-12$ \\
\hline Antithrombin-III, \% & $90.0 \pm 6.6$ & $76.1 \pm 6.8$ & $75-120$ \\
\hline
\end{tabular}

Note: ${ }^{*}$ - the difference is significant in relation to the value in the comparison group $(p<0.05)$ 
The analysis of the data from the Tab. 1 was started from the statistically significant different parameter between the study groups, where the values of patients showed the normal distribution of the variants, - the activated partial thromboplastin time was significantly prolonged in the main group. While in the comparison group the mean value was just in the limits of the reference values range, in the main group it really exceeded the upper border that could be threatening for hemorrhagic events development. The obtaining data indicates a slowing of coagulation in the intrinsic pathway.

In turn, XIIa-dependent fibrinolysis has also shown the statistically significant difference between the study groups but not the normal distribution of the variants inside the study groups. There was present a high standard deviation of the mean value in the main group. The shortening of XIIa-dependent fibrinolysis less than 5 minutes long was found in 7 patients ( $35 \%$ ) of the main group, and only 1 patient $(5 \%)$ from the comparison group demonstrated such a result of this parameter. The brief intermediate conclusion can be made: enhanced XIIa-dependent fibrinolysis and slowing of coagulation in the intrinsic pathway together show the tendency towards bleeding in the main group. The blood clot forms slower, but concomitantly fibrinolysis occurs more quickly.

In continuation of the analysis, the rest of the indices were assessed. The thrombin time was slightly shorter in the main group than in the comparison one, but the difference between the groups did not reach statistical significance ( $p>0.05)$. Such a finding could be controversial in relation to the data on activated partial thromboplastin time and international normalized ratio. There was observed a slowing of the intrinsic pathway of coagulation system and comparable data between the study groups in relation to the extrinsic pathway characterized by international normalized ratio. The reason for this could be in the presence of more developed atherosclerosis in this category of patients in the main group that was shown in our previous works [17]. It is known that atherosclerosis leads to the involvement of additional mechanisms of thrombin formation and also diminishes the antithrombin-III index.

However, the level of antithrombin-III in the main group was relatively bigger than in the comparison one. The mean value in the main group did not exceed the upper margin of the reference range for this parameter. Nevertheless, in 5 patients $(25 \%)$ the increased level of antithrombin-III is of concern because it was more than $120 \%$. On contrary, in the comparison group there were 2 patients $(10 \%)$ with the antithrombin-III index over $120 \%$, but the mean value for the whole group was approximately at the lower border of the normal values range for the index. As antithrombin-III has the main inhibitory (anticoagulant) effect on blood coagulation processes, it is the main plasma protein in the mechanism of thrombin inactivation. The protein $\mathrm{C}$ plays also a great role in preventing coagulation process. Comparing to antithrombin-III it has shown practically equal values for both study groups with the location of the mean value nearby the upper margin of the normal values range. The soluble fibrin-monomer complexes was one more index, which showed neither difference between the study groups nor at least the tendency towards it.
The final assessment of the data from the Table 1 related to the fibrinogen level. The mean value of it was $11 \%$ smaller in the main group than in the comparison one but the big standard deviation of the both indices did not permit to find the statistically significant difference between the study groups. Given that, the further analysis of two groups was performed on quantifying the number of persons in each of them, which had at least one among the following four indices apart from the reference values range in the 'pro-bleeding' direction: activated partial thromboplastin time $>48 \mathrm{~s}$, XIIa-dependent fibrinolysis $<5$ min, fibrinogen $<2 \mathrm{~g} / \mathrm{l}$, or antithrombin-III $>120 \%$. The first two of them were chosen because of the statistically significant difference between the study groups. The last two of them were chosen due to the big standard deviation of the indices that did not permit to find the statistically significant difference. Noteworthy, $100 \%$ of patients from the main group had at least one of the above-mentioned 'pro-bleeding' signs, $50 \%$ of them two or more of such parameters. The percentage of the representatives from the comparison group was $65 \%$ and $15 \%$, respectively ( $\mathrm{p}<0,05$ for both cases).

\section{Discussion of research results}

As the patients were in the stable phase after the hemorrhagic stroke their indices of coagulation hemostasis were at the basic level. Our findings could provide the scientists and physicians with more precise information concerning the prevalence of tendency to bleeding in hypertensive patients after hemorrhagic stroke. The extrinsic coagulation pathway is probably enhanced by the atherosclerotic process, as it is leading in the influence of atherosclerosis on the coagulation hemostasis system and acts as a trigger for further avalanche-like enhancement of blood coagulation due to the intrinsic pathway [18]. In the main group this "trigger mechanism" on tissue damage works normally - the international normalized ratio is not different relatively to the comparison group - but further amplification of thrombin through the activation of the intrinsic pathway [19] is slowed down. Moreover, the blood clot is less stable as it is prone to pass fibrinolysis more quickly. That is why the "anti-bleeding" agents may not be enough to cover the urgent need in hemostasis at the critical moment of vascular damage, for example in case of rapid rise of blood pressure with pulse wave overload, which occurs in such patients [17]. Besides that, different patients had hemostasis disturbances towards bleeding on different levels: hemostasis system itself, anticoagulation and fibrinolysis systems, - that requires further evaluation of these changes.

Few studies have been conducted on the extent to which coagulation hemostasis phenomena are characteristic of people with hemorrhagic stroke [11]. There conclusions are of a little bit different findings and interpretation: as EH progresses, hypercoagulation of blood increases due to reduced anticoagulant activity and depression of fibrinolysis, which leads to an increased risk of complications from the cardiovascular system [11]. It was found an antithrombin-III decrease and D-dimer increase in this category of patients in the period 612 months after the hemorrhagic stroke incidence with further normalization in the later period [11]. However, different patients were assessed in different periods after 
the hemorrhagic stroke. It could be possible that patients, who have had greater disturbances of hemostasis, resulted in re-hemorrhage during the first year after the stroke with the lethal consequence. That is why the authors of the investigation have analyzed only survivors in the later periods, who, possibly, have had better coagulation hemostasis parameters, and that is why less risk of rebleeding. For further investigations, it could be valuable to assess the same patients' coagulation indices in dynamics and to find out the most risk-prone factor for rebleeding. Although it is known that starting from the late rehabilitation period $(>6$ months after hemorrhagic stroke) the risk of recurrent hemorrhagic stroke is reduced [20], however, a group of measures should be taken to prevent further complications of EH in this category of patients, including prevention of atherosclerosis progression.

According to our previous aggregate findings the component of treatment of patients of the main group should be lipid-lowering therapy [2, 17]. International guidelines $[21,22]$ state that a more intense reduction in lipid levels with statins is associated with a lower risk of stroke compared to less intensive treatment regimens. Concerns about the increased risk of hemorrhagic stroke with statin therapy are not justified, but the etiology of stroke may affect the response to statin therapy. In patients with atherothrombosis, which underlies their cerebrovascular events, such treatment is most effective, while those who have suffered a hemorrhagic stroke may not respond positively to such treatment [3]. One USA statin therapy guideline states that the risk of hemorrhagic stroke is increased but the overall cardiovascular risk decreases [4]. In another guideline it was shown that there was insufficient data to recommend limiting the use of statins in patients with intracerebral hemorrhage (class IIb; level of evidence C) [23]. However, it was shown that among other statins, rosuvastatin has a lower risk of recurrent hemorrhagic stroke over a long follow-up period (10 years) [10].

To resume this section, the indicated findings should be taken into account in clinical practice. Prescribing the medications, which influence coagulation hemostasis in this category of patients after the event of hemorrhagic stroke, needs the detailed analysis of coagulation hemostasis panel.

Study limitations. There were several limitations of the study which should be highlighted. There was assessed only those patients with hemorrhagic stroke who had the possibility to transport to the investigation center. Those ones who were under the 50 points of Barthel scale were not recruited into the study. We did not ob- serve patients at the specific one equal quantity of months after the onset of a hemorrhagic stroke because of the severity of the condition and, hence, the possibility of the patient to choose the date for attendance of the clinic. Besides that, there could be valuable to observe separately coagulation panel indices in patients of two types of hemorrhagic stroke - subarachnoid hemorrhage and intracerebral hemorrhage.

Prospects for further research. For further research, there exist plans to find out the peculiarities of coagulation hemostasis indices in hypertensive patients with different types of hemorrhagic stroke - subarachnoid hemorrhage and intracerebral haemorrhage. Besides that, it is going to be planned to assess the influence of statin treatment on coagulation hemostasis in long-term management of this category of patients according to the formula for LDL decrease, proposed in one of our previous studies [24]. It would be of high scientific and practical value to investigate the level of activity of each factor of the intrinsic hemostasis and fibrinolysis system separately in order to identify the most prone to hemorrhagic stroke group of hypertensive patients.

\section{Conclusions}

1. As a result of the obtained data there was found a significantly bigger value for activated partial thromboplastin time in the main group than in the comparison one: $50.38 \pm 2.07$ and $44.67 \pm 1.83 \mathrm{~s}$, respectively $(\mathrm{p}<0.05)$. In turn, XIIa-dependent fibrinolysis lasted in the main group $6.33 \pm 0.93 \mathrm{~min}$ while $10.15 \pm 0.59 \mathrm{~min}$ in the comparison one $(\mathrm{p}<0.05)$. There could be made a conclusion concerning the slow internal pathway of coagulation hemostasis in the main group with the predisposition to quick fibrinolysis relatively to the comparison group.

2. As a result of our study, there was detected that $100 \%$ of patients from the main group had at least one of the following factors out of normal values and with predisposition to bleeding: activated partial thromboplastin time $>48 \mathrm{~s}$, XIIa-dependent fibrinolysis $<5 \mathrm{~min}$, fibrinogen $<2 \mathrm{~g} / \mathrm{l}$, or antithrombin-III $>120 \%$. $50 \%$ of them had two or more such parameters. The percentage of the representatives from the comparison group was $65 \%$ and $15 \%$, respectively ( $<<0,05$ for both cases).

This information should be taken into account while prescribing the treatment, influencing hemostasis indices, in a category of hypertensive patients after hemorrhagic stroke.

\section{Conflict of interests}

The authors declare that they have no conflicts of interest.

\section{References}

1. Holdovskyi, B. M., Darii, V. I., Serikov, K. V., Potalov, S. O., Lovkin, O. A., Sid, Ye. V., Lohvynenko, H. V. (2015). Udoskonalennia monitorynhu ta intensyvnoi terapii multyorhannykh porushen u krytychnykh khvorykh z hemorahichnym insultom. Aktualni pytannia medychnoi nauky ta praktyky, 82 (1 (1)), 16-23.

2. Tkachyshyn, O. V. (2018). Ultrasonic evaluation of hemodynamics and morphology of the major arteries of the neck in patients with essential hypertension associated with hemorrhagic stroke. Ukrainian Neurosurgical Journal, 2, 69-78. doi: http://doi.org/10.25305/unj.129636

3. Catapano, A. L., Graham, I., De Backer, G., Wiklund, O., Chapman, M. J., Drexel, H. et. al. (2016). 2016 ESC/EAS Guidelines for the Management of Dyslipidaemias. European Heart Journal, 37 (39), 2999-3058. doi: http://doi.org/10.1093/eurheartj/ehw272

4. Jellinger, P. S., Handelsman, Y., Rosenblit, P. D., Bloomgarden, Z. T., Fonseca, V. A., Garber, A. J. et. al. (2017). American Association of Clinical Endocrinologists and American College of Endocrinology Guidelines for Management of Dyslipidemia and Prevention of Cardiovascular Disease. Endocrine Practice, 23, 1-87. doi: http://doi.org/10.4158/ep171764.appgl 
5. Kiser, T., Van Matre, E., Sherman, D. (2016). Management of intracerebral hemorrhage - use of statins. Vascular Health and Risk Management, 12, 153-161. doi: http://doi.org/10.2147/vhrm.s75399

6. Chen, Y.-W., Li, C.-H., Yang, C.-D., Liu, C.-H., Chen, C.-H. et. al. (2017). Low cholesterol level associated with severity and outcome of spontaneous intracerebral hemorrhage: Results from Taiwan Stroke Registry. PLOS ONE, 12 (4), e0171379. doi: http://doi.org/10.1371/journal.pone.0171379

7. Mach, F., Ray, K. K., Wiklund, O., Corsini, A., Catapano, A. L. et. al. (2018). Adverse effects of statin therapy: perception vs. the evidence - focus on glucose homeostasis, cognitive, renal and hepatic function, haemorrhagic stroke and cataract. European Heart Journal, 39 (27), 2526-2539. doi: http://doi.org/10.1093/eurheartj/ehy182

8. Orsi, F. A., Biedermann, J. S., Kruip, M. J. H. A., Meer, F. J., Rosendaal, F. R., Hylckama Vlieg, A. et. al. (2019). Rosuvastatin use reduces thrombin generation potential in patients with venous thromboembolism: a randomized controlled trial. Journal of Thrombosis and Haemostasis, 17 (2), 319-328. doi: http://doi.org/10.1111/jth.14364

9. Schrag, M., Kirshner, H. (2020). Management of Intracerebral Hemorrhage. Journal of the American College of Cardiology, 75 (15), 1819-1831. doi: http://doi.org/10.1016/j.jacc.2019.10.066

10. Tai, S., Lin, F., Lee, C., Chang, C., Wu, M., Chien, C. (2016). Statin use after intracerebral hemorrhage: a 10 year nationwide cohort study. Brain and Behavior, 6 (8). doi: http://doi.org/10.1002/brb3.487

11. Mirsaeva, G. Kh., Khakimova, R. A. (2014). Otsenka sostoianiia antikoaguliantnoi i fibrinoliticheskoi sistem krovi u patsientov s arterialnoi gipertenziei III stadii. Kazanskii meditsinskii zhurnal, 95 (5), 621-625.

12. Ye, X., Ye, B. (2016). Association between the Val34Leu polymorphism in blood coagulation factor XIII-A and intracerebral hemorrhage: a meta-analysis. Genetics and Molecular Research, 15 (3). doi: http://doi.org/10.4238/gmr.15038327

13. Sirenko, Yu. M., Mishchenko, L. A., Yena, L. M., Koval, S. M., Radchenko, H. D., Rekovets, O. L. (2018). Classification and standards of providing medical care for patients with arterial hypertension of the Ukrainian Association of Cardiology. HYPERTENSION, 4 (60), 26-47. doi: http://doi.org/10.22141/2224-1485.4.60.2018.141955

14. Liu, C.-H., Lin, Y.-S., Chi, C.-C., Liou, C.-W., Lee, J.-D., Peng, T.-I., Lee, T.-H. (2018). Choices for long-term hypertensive control in patients after first-ever hemorrhagic stroke: a nationwide cohort study. Therapeutic Advances in Neurological Disorders, 11, 175628641880268. doi: http://doi.org/10.1177/1756286418802688

15. Berkovskii, A. L., Sergeeva, E. V., Prostakova, T. M., Melkumian, A. L., Suvorov, A. V. (2016). Skriningovye testy plazmennogo gemostaza protrombinovoe vremia, ACHTV, trombinovoe vremia, fibrinogen. Moscow, 1-70.

16. Kunnakattu, S.-J., Groß, T., Knieps, J., Kemper, T., Fennrich, S., Rauch, N. et. al. (2018). Dynamic and Quantitative Assessment of Blood Coagulation Status with an Oscillatory Rheometer. Applied Sciences, 8 (1), 84. doi: http://doi.org/10.3390/app8010084

17. Netiazhenko, V., Tkachyshyn, O., Tkachyshyna, N. (2021). Factors of the major cervical arteries atherosclerosis progression in patients after hemorrhagic stroke incidence as a result of essential hypertension complication. Norwegian Journal of development of the International Science, 2 (53), 50-60. doi: http://doi.org/10.24412/3453-9875-2021-53-2-50-60

18. Jiang, P., Xue, D., Zhang, Y., Ye, L., Liu, Y., Makale, M. et. al. (2014) The extrinsic coagulation cascade and tissue factor pathway inhibitor in macrophages: A potential therapeutic opportunity for atherosclerotic thrombosis. Thrombosis Research, 133 (4), 657-666. doi: http://doi.org/10.1016/j.thromres.2014.01.012

19. Mackman, N. (2016). The Clot Thickens in Atherosclerosis. Arteriosclerosis, thrombosis, and vascular biology, 36 (3), 425-426. doi: http://doi.org/10.1161/ATVBAHA.116.307094

20. Unifikovanyi klinichnyi protokol ekstrenoi, pervynnoi, vtorynnoi (spetsializovanoi), tretynnoi (vysokospetsializovanoi) medychnoi dopomohy ta medychnoi reabilitatsii «Hemorahichnyi insult (vnutrishno mozkova hematoma, anevryzmalnyi subarakhnoidalnyi krovovylyv)». (2014) Nakaz Ministerstva okhorony zdorovia Ukrainy No. 275. 17.04.2014.

21. Lundervik, M., Fromm, A., Haaland, Ø. A., Waje-Andreassen, U., Svendsen, F., Thomassen, L., Helland, C. A. (2014). Carotid intima-media thickness--a potential predictor for rupture risk of intracranial aneurysms. International journal of stroke, 9 (7), 866-872. doi: http://doi.org/10.1111/ijs.12159

22. Nordestgaard, B. G., Langlois, M. R., Langsted, A., Chapman, M. J., Aakre, K. M., Baum, H. et. al. (2020). Quantifying atherogenic lipoproteins for lipid-lowering strategies: Consensus-based recommendations from EAS and EFLM. Atherosclerosis, 294, 46-61. doi: http://doi.org/10.1016/j.atherosclerosis.2019.12.005

23. Hemphill, J. C., Greenberg, S. M., Anderson, C. S., Becker, K., Bendok, B. R., Cushman, M. et. al. (2015). Guidelines for the Management of Spontaneous Intracerebral Hemorrhage: A Guideline for Healthcare Professionals From the American Heart Association/American Stroke Association. Stroke, 46 (7), 2032-2060. doi: http://doi.org/10.1161/str.0000000000000069

Received date 03.12.2020

Accepted date 25.12.2020

Published date 30.01.2021

Oleksandr Tkachyshyn, Assistant, Department of Propedeutics of Internal Medicine No. 1, Bogomolets National Medical University, T. Shevchenko blvd., 13, Kyiv, Ukraine, 01601

E-mail: tkachyshyn.a@gmail.com 